Revista de la red interuniversitaria de estudios sobre las literaturas rioplatenses contemporáneas en Francia

$23 \mid 2021$

La vereda de enfrente. Cruces entre las literaturas argentina y chilena del siglo XX

\title{
G. E. Hudson en la revista Babel: reconversiones universalistas desde América Latina
}

G. E. Hudson dans la revue Babel: les reconversions universalistes d'Amérique Latine

G. E. Hudson in Babel magazine: universalist reconversions from Latin America

\section{Pablo Concha Ferreccio}

\section{(2) OpenEdition}

\section{Journals}

Edición electrónica

URL: https://journals.openedition.org/lirico/11132

DOI: 10.4000/lirico.11132

ISSN: 2262-8339

Editor

Réseau interuniversitaire d'étude des littératures contemporaines du Río de la Plata

Referencia electrónica

Pablo Concha Ferreccio, «G. E. Hudson en la revista Babel: reconversiones universalistas desde América Latina», Cuadernos LIRICO [En línea], 23 | 2021, Publicado el 12 diciembre 2021, consultado el 07 enero 2022. URL: http://journals.openedition.org/lirico/11132 ; DOI: https://doi.org/10.4000/lirico. 11132

Este documento fue generado automáticamente el 7 enero 2022.

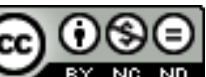

Cuadernos LIRICO está distribuido bajo una Licencia Creative Commons Atribución-NoComercialSinDerivar 4.0 Internacional. 


\title{
G. E. Hudson en la revista Babel: reconversiones universalistas desde América Latina
}

\author{
G. E. Hudson dans la revue Babel: les reconversions universalistes d'Amérique \\ Latine \\ G. E. Hudson in Babel magazine: universalist reconversions from Latin America
}

\author{
Pablo Concha Ferreccio
}

1 Desde fines de la década del veinte, Enrique Espinoza ${ }^{1}$ se había entregado a una de sus más apasionadas campañas de reivindicación literario-cultural: la repatriación del escritor inglés Guillermo Enrique Hudson, quien había pasado su infancia y juventud en la pampa argentina y había dedicado buena parte de sus posteriores textos literarios a retratarla ${ }^{2}$. Tal empresa fue particularmente enérgica en Santiago de Chile, donde Espinoza vivía desde 1935 y ante cuyo público introdujo a Hudson por medio de dos homenajes en su honor, uno en la revista de la Sociedad de Escritores de Chile (SECH) en 1937; el otro, cuatro años más tarde, en la revista Babel.

2 En este artículo me interesa sobre todo el segundo homenaje, pues allí podemos leer un conjunto de posiciones que enriquecen -y que van más allá de la interpretación corriente de Hudson en Argentina- una mirada sobre su obra que no se decidía a exceder coordenadas nacionales o, a lo sumo, rioplatenses. En las páginas de Babel, revista que el mismo Espinoza dirigía desde la capital chilena ${ }^{3}$, advertimos varias de las valencias que el nombre y la obra de Hudson tuvieron para pensar la cultura latinoamericana de su época. Allí participaron no solo autores argentinos o que podemos encontrar en empresas editoriales previas de Espinoza (los poetas Luis Franco y Hernán Gómez), sino que además los narradores Manuel Rojas y Ernesto Montenegro, chilenos, y Ciro Alegría, peruano.

El rescate de la obra de Hudson para Latinoamérica y el carácter transnacional de las redes en que participa Espinoza permiten pensar las prácticas editoriales de Babel desde el debate actual sobre literatura mundial. Con un énfasis en la realidad 
latinoamericana, Mariano Siskind propone comprender este concepto como "la formación material y dinámica de un campo global de intercambios materiales y simbólicos en el que los escritores y textos latinoamericanos negocian activamente los términos de su participación en dicho proceso histórico-mundial" (2016: 38). El proyecto de Babel en Chile hace parte de múltiples esfuerzos culturales y políticos de entreguerras que buscan repensar la identidad, la posición y el papel que juega Latinoamérica en un reparto geopolítico mundial, cuyo eje se desplaza de Europa a Estados Unidos, marcado por el diagnóstico del agotamiento de la civilización occidental. En ese contexto, Antonia Viu ha afirmado que la revista asume la formación de un "parentesco espiritual" o de una "comunidad afectiva" que le permite a "los intelectuales latinoamericanos [insertarse] discursivamente en un lugar de igualdad en el contexto de la Segunda Guerra Mundial" (2018: 426).

Considero la canonización argentina de Hudson como una de las operaciones con que el grupo intelectual de Babel contribuye a repensar la identidad cultural latinoamericana en un marco mundial, entendiendo "mundo" como una construcción cultural que alude a una totalidad de sentido (Nancy 2007: 41) inestable y en permanente disputa. Si las políticas editoriales son capaces de construir o de proyectar un espacio simbólico que reordena los límites geográficos (Pita González 2016: 15), la reconquista del inglés -como la llama Espinoza- supone una idea de mundo guiado por un universalismo que se quiere nuevo, pero que insiste sobre todo en la habilitación de la tradición literaria argentina en la civilización occidental. Ahora bien, la lectura de Hudson adopta en las páginas de Babel un carácter explícitamente continentalista y un universalismo determinado, que tensiona y en último término excede la propuesta puntual de Espinoza. Como veremos, Espinoza hace hincapié en una lectura más directamente histórico-política de Hudson, mientras que los autores no argentinos se concentrarán en la relación humano-naturaleza, que caracteriza la obra de Hudson, para proponer su valía contemporánea.

5 Este artículo cuenta con dos apartados, cada uno de los cuales privilegia una arista particular del fenómeno de la literatura mundial. En el primero reviso algunas estrategias enunciativas del ensayo de Espinoza, "La reconquista de Hudson", cuyo valor programático y genético servirá para introducir los usos e interpretaciones que el editor hace de Hudson a lo largo del tiempo. En la segunda parte integro a la discusión sobre hermenéutica el rol de las redes intelectuales de Babel, aspecto que permitirá enriquecer nuestra comprensión de la significación del rescate de Hudson hacia 1941, al relacionar su nombre y obra con diversos lugares de enunciación y con una coyuntura estético-política central en la época ${ }^{4}$.

\section{La reconquista de un gaucho inglés}

"La reconquista de Hudson" fue publicado en 1934, primero en La Nación de Buenos Aires (10 de junio) y luego en Repertorio Americano (20 de octubre). El hecho de que Espinoza dé por terminado su texto siete años después de su primera versión, en 1941, y el que su escritura se encuentre a caballo entre dos espacios culturales distintos, nos puede decir algo sobre los acomodos enunciativos que tanto practicaba (en este caso, con sus propios textos) ${ }^{5}$ y sobre sus cambios y énfasis interpretativos respecto de la obra de Hudson. De las tres secciones que presenta "La reconquista de Hudson" en 1934, la versión de 1941 conserva tan solo la primera, con retoques estilísticos y 
adiciones. La versión chilena cuadruplica en extensión a la argentina y sus objetivos varían; el ensayo mantiene su tesis central pero modifica enteramente desarrollo y argumentos. Si el artículo de La Nación reclama la reconquista genuina de Hudson para la Argentina en clave nacional-popular, el ensayo de Babel busca convencer a una nueva comunidad de lectores acerca del valor literario y cultural de Hudson en términos universales.

7 La principal arma que serviría a dicha reconquista en 1934 es la traducción sistemática del clásico inglés a la lengua castellana y su amplia difusión por el territorio nacional. En 1941 Espinoza aún se queja de la escasez de traducciones (pasa revista a sus vicisitudes bibliográficas: qué se ha escrito sobre él y qué se ha traducido), pero su atención se dirige sobre todo al valor literario de la literatura hudsoniana y no tanto a su situación en el medio literario. El cambio de énfasis se da, en parte, por la mayor difusión que ha logrado Hudson gracias a las traducciones de Fernando Pozzo en Argentina y de Ernesto Montenegro en Chile ${ }^{6}$, pero también por la presencia de firmas chilenas que respaldan la valía del autor en el homenaje. Aun cuando es un ensayo de interpretación con pretensiones de universalidad mayores, la argumentación de Espinoza suele volver sobre los tópicos que habían guiado su homenaje en SECH: la anhelada (re)criollización de Hudson, su valor testimonial para comprender una parte de la historia argentina, su hondura psicológica para expresar la mentalidad del hombre de la pampa (Espinoza 1937).

\section{El criollismo: de negociación a crítica}

8 Otro de los aspectos nuevos de la versión de 1941 es una particular insistencia en la crítica a la literatura regionalista, que se puede sintetizar en dos aspectos: el primero de ellos y el más abundante se refiere a la reprobación del uso de lenguaje local en estas novelas y cuentos, ya sea en términos léxicos o bien a través de la escritura fonética ${ }^{7}$; el segundo corresponde al tratamiento de las intrigas amorosas en La tierra purpúrea. La siguiente cita muestra ambos:

Pero ¡qué diferente La tierra purpúrea de esas novelas criollistas hoy en boga! Hudson obtiene sus mejores efectos huyendo justamente de lo pintoresco y adentrándose en el reino del corazón, como él mismo dice, al analizar los sentimientos humanos más perdurables. No le interesan las acuarelas sentimentales. (Espinoza1941b:72).

9 La reprobación del lenguaje local, por efectista, merece el elogio de Espinoza en dos oportunidades, con referencia a la traducción de Montenegro. Por contraste, Espinoza afirma que "Hudson condena [...] todos los trucos del criollismo y de la gauchería" (1941b: 81), con lo que despacha en bloque los vicios de una narrativa superficial a un lado y otro de la cordillera. Respecto de las "acuarelas sentimentales", Espinoza critica la dinámica relacional entre los géneros que se da en el criollismo. Si es cierto que el crítico comparte la vieja metáfora de la tierra (en este caso, la tierra purpúrea) como una hermosa mujer que enamora a Mr. Abel -el otrora colono que protagoniza la novela-, también es cierto que este amor no perpetúa el sino de explotación colonial que caracteriza a las ficciones de la tierra ${ }^{8}$. Las mujeres de la selva que se enamoran de Mr. Abel no son consumidas por él, sino que "vuelan a su alrededor sin quemarse como espléndidas mariposas en torno de una alta luz" (1941b: 73). Esta notable observación sobre el problema del género exhibe el nivel de comprensión de Espinoza sobre el criollismo, pero también su habilidad para iluminar la lógica de diferenciación, de 
distinción (Sapiro 2016), que guía la difusión de Hudson en Chile respecto de la corriente literaria hegemónica.

La crítica abierta al criollismo puede leerse en la coyuntura que decide la connotación política de esta estética a fines de la década. Si en 1937 el imaginario ligado a la vida y a los valores rurales era disputado por terratenientes conservadores y reformistas clasemedieros, el triunfo del Frente Popular (coalición de comunistas, socialistas y radicales) en las elecciones presidenciales inclinó la balanza hacia la izquierda, pero también institucionalizó al criollismo: "[e]l idealismo rural y las representaciones culturales nacionalistas de la vida campesina, avaladas por el Estado, se convirtieron en componentes oficiales de la identidad nacional chilena" (Barr-Melej 2010: 121). El encumbramiento del criollismo a estética de Estado terminó de sancionar la pasividad de la figura del huaso, su consideración objetual, acompañada de un paternalismo reformista que combatía las ideologías capaces de "corromperlo" (125-126). La superficialidad de la representación del huaso (o del gaucho, en Argentina) implicaba precisamente una domesticación cultural que Espinoza, afín a un socialismo trotskista, no podía consentir. En el homenaje de SECH Espinoza había presentado a Hudson haciendo guiños a la tradición criollista, pero deslizando críticas tácitas ${ }^{9}$. En el de Babel ya no hay rastros de una negociación estético-política como aquella, sino tan solo crítica mordaz.

\section{Espinoza, banquero de las letras universales}

11 "La reconquista de Hudson" (1941) retoma su tesis de 1934 con una importante modificación que hace hincapié en el aspecto local: "es mediante una versión del espíritu criollo de su obra -por lo menos de una parte de ella- que se puede reconquistar a Hudson como clásico de nuestra literatura" (1941b: 70); en 1934 leemos solamente "una versión genuina del espíritu de su obra" (233). La deseada universalidad de Hudson se debe a que es capaz de interpretar no cualquier espíritu, sino concretamente el argentino. Ello habilita que una especificidad cultural periférica pueda participar de una idea de lo mundial, al reducir la distancia entre lo particular y lo universal. Esto es complementario con una afirmación sobre la universalidad de Hudson que escribiera poco antes. Allí Espinoza afirma que el puente entre sus dos etapas vitales -infancia y juventud pamperas, madurez y vejez londinenses- "es el espíritu universal de Hudson" (1932: 78). Es decir, el espíritu universal no se encontraría ni en la experiencia de la pampa ni en la mirada rememorativa que la recrea desde el centro, sino que se produce en el entre que las comunica, en ese hiato que Espinoza busca suturar.

Esta "versión del espíritu criollo", aquel "entre" universalizante, es sugerido en 1941 como un asunto político-cultural vinculado directamente con la posición de América Latina en el nuevo reparto mundial:

¿Es preciso agregar después de cuanto llevamos dicho y recordado que Hudson el naturalista, no es ningún discípulo ingenuo de Rousseau? El mundo agreste y feroz de sus libros americanos es apenas romántico y nada revolucionario. Está de acuerdo con la naturaleza en general y con la suya en particular. [...] el maestro de Allá lejos... fue ajeno a todo arrebato como escritor y como hombre. Empero, aquel no es pacifista ni éste, vegetariano. Ambos comprendieron a un tiempo el fenómeno antinatural del capitalismo invasor en carne y espíritu. (Espinoza 1941b: 85) 
Espinoza interpreta el problema de la naturaleza en Hudson desde el marco del anticapitalismo. La relación que propondría el inglés entre humano y mundo estaría dada por una crítica política: Mr. Abel, protagonista de Mansiones verdes, sería un "nuevo romano imperialista [que] no lo era de corazón" (1941b: 71), pues logra desalienarse del capitalismo que lo ha conducido a la selva amazónica. Se vuelve un aliado de la naturaleza, de la barbarie. Con esto, Espinoza hace entrar la discusión contingente sobre colonialismo e imperialismo, muy vigente en su propia época (además de partir aguas definitivamente con la interpretación de Hudson hecha por el grupo Sur en Argentina). Ahora bien, es curioso que la crítica vaya incluso más allá de la política, para adentrarse en terreno antropológico: "El mundo agreste y feroz [...] Está de acuerdo con la naturaleza en general y con la suya en particular". Si leemos esto en el marco de la crisis civilizatoria de occidente que marca la agenda intelectual de la época, podemos interpretar que es en el "entre" propio de una nueva relación humanonaturaleza que podría surgir otra cultura, un mundo nuevo, capaz de superarla.

La circulación de Hudson a través de Babel es una de las herramientas para hacerlo posible. Hay razones para pensar que a Espinoza no se le escondía la importancia de su figura en ese tránsito. Al destacar el valor de Far Away and Long Ago (las memorias de Hudson), Espinoza retoma una interesante metáfora de Robert Cunninghame Graham ${ }^{10}$ :

"Quizá las neblinas de los años fueron en realidad el alambique que consumió todo lo que no merecía ser referido, dejándonos el oro puro".

Este oro puro, amonedado desde un principio en cuño extranjero, puede por fortuna ser convertible como el de la Banca, en patrón y resguardo de nuestras letras de crédito y esperanza, para no abusar más del símil fiduciario. (1941b: 87)

Espinoza se entusiasma con la comparación pecuniaria, pero refrena su impulso apenas lo advierte. Indaguemos en esta represión. El pasaje tematiza la literatura-dinero como bien cultural convertible y, por tanto, reapropiable nacionalmente. El oro es aquí una entidad espiritual, la experiencia de Hudson, cuya mostración literaria la modifica con cada nueva conversión: de ahí que Hudson sea reconquistable por presentar "una versión [literatura] del espíritu criollo [oro]" (1941b: 70). La reconversión del oro hudsoniano haría ingresar la literatura latinoamericana en el mercado literario mundial, a la vez que universalizaría la experiencia latinoamericana. Ahora bien, la interpretación-administración del oro, esa reserva de riqueza que merece reconocimiento universal (pues habla el mismo lenguaje en todo el mundo), desplaza la clave del problema. La lectura más interesante del pasaje no se centra en la literatura, sino en la figura del agente que hace posible su conversión, ese que garantiza la operación financiera, es decir, la edición, traducción y/o difusión literarias ${ }^{11}$. Quien puede realizar esta conversión es el editor-banca, guardián del oro y responsable de velar porque el valor de la literatura latinoamericana no decaiga en el mercado internacional; es este editor-banca el que emite las "letras de crédito y esperanza" que mantienen viva la economía-institución literaria continental ${ }^{12}$.

Espinoza es muy preciso al caracterizar la metáfora de Cunninghame Graham como "fiduciaria", término proveniente de fiduciarius, cuya raíz es fidus y cuyo campo semántico involucra lealtad, honestidad, confiabilidad (Oxford Latin Dictionary 1968: 699). El editor-banca facilita la conversión y luego lo entrega a un agente de confianza, pero no sabe en qué se convertirá. Solo atendiendo a los textos firmados por escritores en Babel podremos ver cuál es la nueva significación que esa moneda literaria, Hudson, obtiene en el concierto mundial desde América Latina. Si la experiencia-dinero 
hudsoniana se universaliza al reconvertirse, y si hemos visto que ese universalismo pasa por una interrogación por la relación humano-naturaleza, ¿cuál es la forma contingente de tal universalismo? ¿Qué técnica se emplea para pretenderlo? Para responder esta pregunta, considero el aspecto hermenéutico de los artículos de autores no argentinos en el homenaje de Babel, así como la dinámica de redes que lo hicieron posible.

\section{El Hudson de Babel}

\section{El control hermenéutico bonaerense}

Como dijimos, en el homenaje de Babel hay gran variedad de nacionalidades: participan tres argentinos, dos chilenos y un peruano. En este sentido, cabe observar la diagramación de la tapa de la revista, que desde su refundación chilena incluye al pie los que pueden considerarse índices onomásticos que manifiestan una red geocultural (ver fig. 1). ¿Cuál es la relación entre Buenos Aires, Santiago y Nueva York? Cada uno de estos nombres remite a un lugar de enunciación determinado político-afectivamente en el proyecto babélico. En el caso del número 18, dedicado a Hudson, lo que se observa es una fuerte tensión entre los vínculos que Espinoza mantiene con distintos agentes nucleados en torno a las tres ciudades y sus respectivos países.

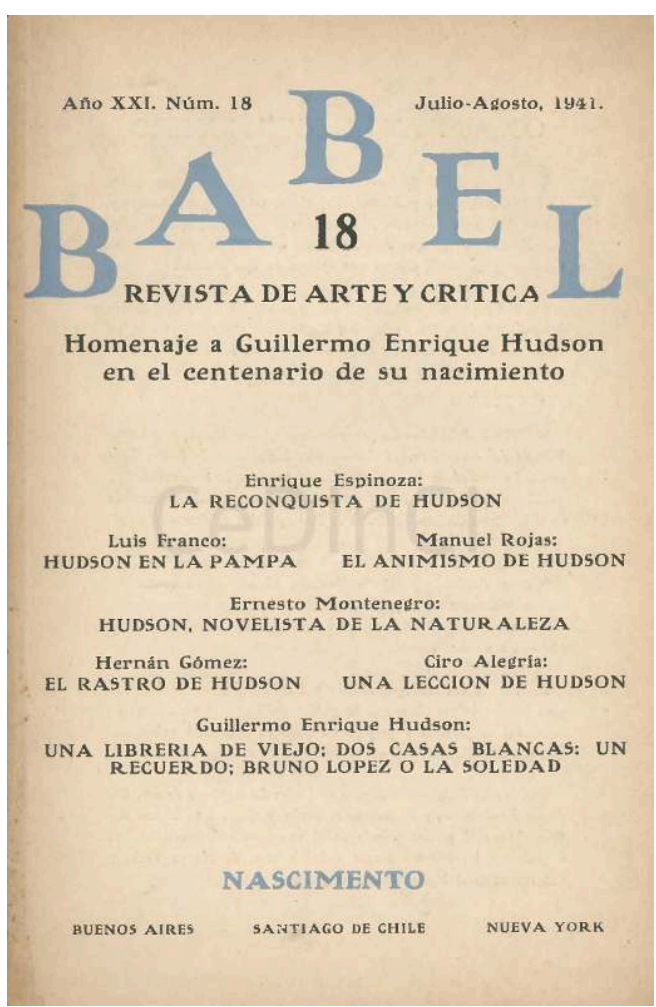

Fig. 1. Portada del número 18 (julio-agosto 1941) de la revista Babel.

La más evidente tirantez relacional se da entre Espinoza y su red argentina. Desde Buenos Aires, Oscar Cohan, traductor del latín, alemán e inglés, y amigo suyo, desaprueba enteramente la idea de un homenaje a Hudson en Chile: "No me gusta la idea de dedicarle un número especial a Hudson. Ahora que son legión los hudsonianos tipo Dr. Pozzo dejemos la misión a estos explotadores quilmeses y sus circunvecinos" 
(14/04/1941). Como es claro, el argumento se basa en una consideración exclusiva de la recepción argentina de Hudson. La crítica de Cohan se dirige a un modo de canonización auspiciado por el estado y de carácter patrimonialista, además de estar ligado al grupo Sur, cercano a una "oligarquía criollista" (Lencina 2017: s/p) ${ }^{13}$. Asimismo, el traductor parece al tanto de la estrechez económica de Espinoza, quien desde 1940 paga de su propio bolsillo la mitad de cada volumen (González Vera 1967: 52). Cuando Cohan recibe el que probablemente sea el contundente número en homenaje a Trotsky, le escribe a su amigo: "Recibí y leí el número de B. Es el mejor de la colección y hasta podría servir para dar bello fin a la revista si a Ud. le parece bien" (26/05/1941). Este recelo (Cohan no colaboró con la revista) es bastante más pronunciado en Luis Franco, colaborador histórico de Babel y hermano espiritual de Espinoza:

Respecto al número dedicado a Hudson, estoy en principio con Ud. y no con Cohan: esto es, siempre que en él se inserten dos o tres trabajos que significasen un aporte, es decir, algún aporte nuevo, sobre todo o muy especialmente considerando el lado argentino o gauchesco de Hudson. Creo que Ud. y yo deberíamos asignarnos esa tarea: si a eso agregamos algún buen trabajo como puede escribirlo [Ernesto] Montenegro, y algún otro, creo que el número se justificaría plenamente (01/11/1941 en Tarcus 2009: 290, énfasis suyo).

19 Se trata, pues, de un respaldo condicional a la propuesta. La carta exhibe una voluntad de control sobre la interpretación de Hudson en tierra chilena: Franco no solo sugiere un nombre específico para garantizar la calidad de las contribuciones, sino que además explicita la lectura "correcta" del inglés, afincándola a la línea de reivindicación nacional o criollización cuya campaña era moneda común en Argentina desde 1928. Su postura sobre la interpretación literaria, decididamente militante, pretendía que no se descuidara la dimensión nacional-popular de Hudson. A juzgar por el texto de Espinoza, este pensaba de manera similar. Es justamente la dimensión directamente política lo que está ausente en las intervenciones peruana y chilenas sobre Hudson, y aquello que Franco echa en falta en la línea editorial de la revista (Franco 04/10/1940 en Tarcus 2009: 275-276).

Los textos de Espinoza y Franco van y vienen entre un anhelo de universalidad y un énfasis en la clave nacional-popular; por ejemplo, el primero escribe que la "nostalgia de la tierra nativa impregna toda la obra de Hudson y constituye su mayor encanto" (1941b: 83). Por su parte, Franco no pierde de vista el asunto criollo, pero aborda la relación humano-naturaleza de manera más directa y profunda que Espinoza. En "Hudson en la pampa", propone una interpretación continental del inglés ${ }^{14}$, que no renuncia al gaucho pero que lo sobrepasa y que proyecta la potencia de su literatura en el presente: "Hudson no fué sino un gaucho que no se dejó enredar en la cultura sino que llegó por ella a la plenitud de su expresión espiritual. Y por eso podemos, reivindicar su grandeza como nuestra, y lo que es más, mirarlo como ejemplo de nuestras posibilidades" (1941: 101, énfasis suyo). Franco dedica la mayor parte de su artículo a cómo Hudson descubrió el mundo natural, el papel que sus sentidos jugaron en ello, las formas que adoptó ese vínculo con el tiempo. Hudson destacaría como "el único verdadero sentidor de la pampa" (Franco 1941: 90) y del medio en general, en contraste con las "impresiones de turista" (89) que habrían acumulado los escritores latinoamericanos del siglo XIX (Bello, Echeverría, etc.). Se inscribiría entonces en la línea del Martín Fierro, pero mientras este representa una fuerza inconsciente, Hudson conjuga el instinto con "las más preclaras conciencias del hombre moderno" (Franco 1941: 90) ${ }^{15}$. 


\section{Babel más allá de Espinoza} directamente política de la literatura de Hudson, que por una relación humanonaturaleza con menor anclaje en condiciones de producción determinadas (al menos, a primera vista). La argentinidad espiritual de Hudson está enteramente ausente, y es suplida por una idea de universalidad que, cuando marcada geográficamente, alude al continente americano. Los tres parten de la premisa de una continuidad entre el sujeto histórico que sintió la naturaleza y el problema de la forma literaria. En su artículo "Una lección de Hudson", Alegría confiesa que la lectura del inglés le ha servido para moderar su entusiasmo por las formas del habla local, que afectaba sus producciones previas a El mundo es ancho y ajeno (1941), mientras que Montenegro destaca el estilo del autor como una naturalidad conscientemente elaborada en su obra madura:

si el escritor no reconoce al mismo tiempo las limitaciones de su arte junto con las posibilidades del esfuerzo consciente, jamás llegará probablemente a conocer la satisfacción de una forma eficaz y una creación bien madura. Porque ese estilo hudsoniano que se produce al parecer tan naturalmente como crece la hierba, representa el producto de un conocimiento efectivo del asunto y el esfuerzo empeñoso y paciente por ajustarlo a la elusiva fluidez de la palabra (1941: 109-110).

La dimensión estética se relaciona estrechamente con el tipo de universal en que piensan uno y otro escritor. Alegría reconoce que Hudson lo ha ayudado a superar "la técnica del narrador folklórico, que solo es entendido por su tribu" (1941: 119), pero que ello no implica resignar la identidad nacional que una literatura puede legítimamente pretender: "Lo peculiar de cada sector nacional es precisamente lo que da multiplicidad y riqueza a la vida universal y haremos bien en mostrar lo que somos" (119). Montenegro, en cambio, se refiere a la naturaleza latinoamericana casi en un nivel ontológico -su ser; de hecho, escribe siempre "Naturaleza"- y no entra en la discusión sobre la fidelidad mimética para con un referente extraliterario (Hudson ubica la acción narrativa de Mansiones verdes en la Amazonía, que él no conoció), pues lo que le interesa ante todo es América Latina como unidad cultural. En este sentido, es interesante la siguiente afirmación: "Hudson resumió su concepción de la Naturaleza en la imagen de Rima, la criatura ideal, único sobreviviente de la raza perdida que acaso no está en el pasado sino en el porvenir" (110). Es notable que la universalidad, basada en una relación nueva entre humano y naturaleza, sea una cualidad proyectada hacia el futuro, a la vez que los principales referentes para comprender a Hudson serían Conrad (cuya definición del estilo hudsoniano Montenegro toma) y Whitman, quien comparte su sentir hacia el mundo natural (111).

Para comprender cabalmente estas posiciones cabe destacar una situación importante a nivel de redes (y a nivel de campo, diríamos), que además explica por qué leemos Nueva York a los pies de este número. Es necesario comprender desde dónde están escribiendo Alegría y Montenegro. En la presentación de los autores del número (contratapa 1) se encuentran otros índices: Montenegro está "[a]ctualmente en Nueva York" y "ha publicado numerosos artículos y ensayos en la prensa argentina, chilena y norteamericana", mientras que Alegría "[h]a escrito en Chile: La serpiente de oro, Los perros hambrientos y El mundo es ancho y ajeno. Esta última obtuvo el primer premio en el concurso interamericano que organizaron los editores Farrar and Rinehart, de Nueva York, y fué traducida al inglés, portugués y sueco". En el artículo de Alegría, de hecho, 
se incluye su firma: “Nueva York, julio 6 de 1941" (Alegría 1941: 120). El peruano había viajado a Estados Unidos ese mismo año a recibir el premio y se quedaría siete años trabajando y viajando por el país. En sus cartas a Espinoza de 1941 y 1942 le cuenta de su interés por mejorar su rudimentario inglés y le envía los saludos de Montenegro, que hace de Virgilio por la capital cultural estadounidense.

El premio literario, organizado por la Unión Panamericana, la editorial neoyorkina Farrar \& Rinehart y la revista Redbook Magazine, fue uno de los instrumentos de diplomacia cultural con que se "buscó aminorar el antiimperialismo dominante en la escena intelectual-literaria de América Latina, adversa tradicionalmente al panamericanismo, en tanto identificaba en éste un proyecto de dominación promovido por Estados Unidos" (Carrillo Reveles 2019: 281). La presentación de Alegría que hace Babel reconoce y aprovecha la instancia, pues uno de sus colaboradores se instala en el centro del sistema literario global: su novela ha ganado un concurso en que las redes intelectuales y culturales de América Latina han estado representadas (dato fundamental: ¡Montenegro fue uno de los tres jueces del concurso!), y su internacionalización es garantía de relevancia mundial -en menos de seis meses está traducida a tres idiomas (el fallo del concurso había sido comunicado a inicios de marzo de 1941)-. Uno de los autores más reconocidos de la literatura latinoamericana en el mundo, quien más capital simbólico está generando a nivel internacional, escribe como discípulo de Hudson. De ahí que Alegría asuma desde el comienzo de su artículo un registro de escritor profesional y consagrado, cuya experiencia testimoniada alcanza un rango ejemplarizante. Enunciado desde la primera persona, reconoce el estatus de lo que llama "mi carrera literaria" (1941: 117), “mi evolución” (118). La "lección” de Hudson que él recibe es a su vez proyectada a la literatura latinoamericana toda; la literatura del inglés se vuelve entonces radicalmente contemporánea. Con todo, la esencia espiritual o cultural latinoamericana sigue suponiéndose a priori: la precisión expresiva de Hudson se ajusta a una "esencia" descubierta previamente. Así, Hudson facilitaría una saludable poda para presentar de manera más fiel al hombre latinoamericano. La novela de Alegría alcanza una universalidad que sigue marcada por una idea de autoctonismo - de ahí que su recepción norteamericana valore lo que identifica como "exótico" (Carrillo Reveles 2019: 312 y ss.)-:

Aunque sin caer en extralimitaciones, yo era también bastante aficionado a los regionalismos externos, siendo igualmente cierto que no caía en la puerilidad de superestimarlos y trataba de fundamentar mi obra en otros materiales básicos. Ya en el nuevo camino, que era quizá el mismo que traía pero aclarado y más recto hacia sus objetivos, escribí El mundo es ancho y ajeno" (Alegría 1941: 118).

Montenegro también está en Nueva York, pero su lugar de enunciación es muy distinto. A mitad de la década del treinta su reputación en Estados Unidos es tan sólida que la Fundación Carnegie lo llama para dictar clases de literatura latinoamericana en las universidades de Colorado, Missouri, Florida y Northwestern, de la que es profesor en 1939 y 1940. En paralelo, colabora con el New York Times Book Review, entre otras cosas, escribiendo reseñas de libros de viaje de estadounidenses por América Latina, que pretenden capturar la esencia continental y presentarla al público del norte. Colabora además con otros medios de temática político-social, como The Annals of the American Academy of Political and Social Science, en cuyo volumen 222 (julio de 1942), encontramos su "An Economic Partnership of the Democracies". De modo que el chileno es en Estados Unidos una autoridad en distintas dimensiones de la realidad latinoamericana, que sobrepasan con mucho la especificidad literaria. Esta reconocida amplitud de 
registro le vale la invitación a participar en conferencias acerca de relaciones panamericanas, por ejemplo al alero de la Fundación Tallman en el Bowdoin College (Montenegro 1942: 83). En suma, Montenegro está involucrado en prácticas de diplomacia cultural cuya descripción y alcances aún tenemos pendientes, pero que cubren las principales aristas de la realidad latinoamericana en juego durante la Segunda Guerra Mundial y que lo ponen en contacto con agentes políticos estadounidenses de relevancia ${ }^{16}$.

Este es el autor que escribe "Hudson, novelista de la naturaleza", un mediador clave de Hudson, para América Latina, desde Estados Unidos. La visión de la naturaleza que se advierte en su artículo compone una mirada que se quiere alternativa a los discursos corrientes sobre América Latina en el ecosistema bibliográfico norteamericano ${ }^{17}$. De ahí su visión de la naturaleza que rescata la tradición literaria anglosajona y que proyecta hacia el futuro. Esto podría explicar que, aun cuando la suya es la contribución más breve del homenaje, Espinoza ubique su nombre en el eje central de la diagramación de la tapa. En esa misma columna aparece, respecto del nombre del chileno, el de Espinoza hacia arriba y el de Hudson hacia abajo (ver fig. 1). Si pensamos conjuntamente la retícula de la portada y las redes intelectuales a las que nos envía el número, podemos leer la ubicación intermedia de Montenegro y la significación de su nombre como una restitución simbólica de un olvido revelador en los textos sobre Hudson escritos por latinoamericanos. Este olvido (cuando se lo ha evocado, se lo suele tratar como un dato sin importancia $)^{18}$ corresponde a la tercera ciudadanía de Hudson, pues sus padres habían nacido en Estados Unidos: su padre, en Massachussets; su madre, en Maine. En un momento en que Estados Unidos está planteando un enfoque interamericanista, de relaciones pretendidamente horizontales con sus vecinos del sur, y en que uno de los principales colaboradores de Babel está participando de esas discusiones, es importante pensar la significación mundial de Hudson. considerando el dato de la filiación reprimida. La universalidad hudsoniana de Montenegro lleva implícita la huella de un panamericanismo alternativo.

Por último, Manuel Rojas, desde Chile, es quien lleva más lejos las ideas que aquí hemos revisado. Su punto de partida es el mismo de Montenegro -el vínculo humanonaturaleza como fundante de un mundo por venir-, pero a diferencia de aquel y de Alegría, Rojas no alude a ninguna interioridad espiritual, sea argentina, chilena o continental, para examinarla. En "El animismo de Hudson" se advierte, en cambio, una deuda con el evolucionismo ${ }^{19}$, con el psicoanálisis (Freud y Jung) y con el materialismo spinozista. Rojas interpreta la experiencia del humano con la naturaleza y lo que Hudson llama "animismo", cualidad que juzga como la principal de Hudson. Gracias a esta "facultad primitiva", Hudson penetraría en la naturaleza vegetal o animal: "advirtiendo en ellos y mostrando, con una simpleza casi mágica, la vida y los instintos que los animan". El inglés dice además que tal característica es "la supervivencia de un reflejo de temor y de respeto del hombre primitivo ante la naturaleza" (1941: 104).

Gracias a ella, el hombre se aproxima a anular su distancia con el animal y con las cosas. Se trata de una escucha o empatía radical entre materias, pues el humano no es más que eso en este contexto. La relación, sin embargo, somete al humano sensorialmente; no se reduce al placer de aquel en su medio, sino que consiste en una profundidad de la percepción que aflora cuando el niño es capaz de reparar en su relación con el mundo, cuando comienza a ser consciente de ella. Ante el roce de una serpiente, ante un campo florido, "al placer se unía un inexplicable e insoportable sobrecogimiento y temor" 
(106). De ahí que este instinto sea "de carácter esencialmente religioso" (Hudson en Rojas 1941: 108).

En la década del treinta, Rojas había sido uno de los críticos más lúcidos del criollismo, incluso reconociendo su deuda con y su implicación parcial en él. La lectura de Hudson permite a Rojas dar una respuesta acerca de la representación del humano que involucra el reconocimiento de una forma de autenticidad premoderna, primitivista y universalista. En último término, esto implica repensar esa autenticidad en términos antropológicos. Asimismo, si el personaje latinoamericano se debe a una relación específica con la naturaleza, el modo de darse esa relación acaba perdiendo por completo el dato nacional y se afinca ante todo en una forma de sentir el mundo. En este sentido, es quien más se aleja de Espinoza, pero es también quien más se acerca en su rechazo al criollismo. En una palabra, Rojas puede superar el criollismo reinterpretando su principal preocupación.

\section{Conclusiones}

En este artículo he buscado mostrar la variedad hermenéutica que se lee en Babel, contrapesando la magnitud que ha adquirido la figura de Espinoza para explicar la significación del proyecto editorial. La recepción de una literatura se debe a las condiciones del medio literario e intelectual de la cultura de llegada y al conjunto de intelectuales que la media. Es atendiendo a ello que se puede dar una idea acabada de la riqueza de la lectura de Hudson desde Chile. El homenaje de Babel permite ver el acomodo enunciativo del proyecto de Espinoza entre el contingente que lo acompaña desde la Babel histórica y quienes se incorporan en Santiago, lo que impide postular que la revista publicada en Buenos Aires en los años veinte responda al mismo proyecto que la impresa en Santiago en la década del cuarenta.

Asimismo, he intentado dar cuenta de las inclinaciones político-estéticas que adquiere este nombre en un marco de mundialización y viraje de la literatura latinoamericana. Así se ha abierto una vía interpretativa que repone la clave panamericana, a pesar de que en los años iniciales de la Babel chilena también hay gran conexión con la variante ginebrina de la diplomacia cultural y una genuina preocupación por el destino de Europa. En este sentido, el norte asume la rehabilitación refaccionada de esa cultura moribunda (y es precisamente en 1941 que Estados Unidos entra en la Segunda Guerra Mundial). El estudio de esta veta merece profundizarse, pero por lo pronto notemos que en 1944 se publica en la Revista Hispánica Moderna, que dirige Federico de Onís en la Universidad de Columbia, un homenaje titulado "Guillermo Enrique Hudson visto por los argentinos", el que insiste en la clave nacional de lectura e incluye los textos de Franco y Espinoza publicados en Babel.

En contraste, las interpretaciones de autores no argentinos en Babel hicieron énfasis en la universalidad como un efecto de lectura y, con ello, abrieron la posibilidad de abandonar definitivamente la discusión por la justeza de la mímesis a un referente extraliterario, ejemplarmente notada en la recepción de Manuel Rojas. La universalización de la identidad cultural latinoamericana que anuncia Espinoza en 1932 parece consumarse nueve años más tarde, al precisarse técnica y literariamente. En otras palabras, la universalidad de Hudson sirve a los escritores como una herramienta orientada a la creación literaria. Desde Chile, Hudson se convierte en razón para hablar del mundo y en herramienta para pensar uno nuevo. Un mundo otro, que escape al 
oficialismo político-cultural diseñado desde el norte, pero que tampoco lo expulse de su órbita; que reconozca cierta particularidad latinoamericana, sin por ello reconducirla a los parámetros del folclor ${ }^{20}$.

\section{BIBLIOGRAFÍA}

Alegría, Ciro, “Una lección de Hudson”, Babel, Año XXI, № 18, julio-agosto 1941, p. 117-120.

Barr-Melej, Patrick, "Imaginando el campo: nacionalismo cultural, política y la búsqueda de la chilenidad, 1891-1941”, Gabriel Cid y Alejandro San Francisco, eds., Nacionalismos e identidad nacional en Chile. Siglo XX, vol. 1, Santiago, Centro de Estudios Bicentenario, 2010, 93-130.

Carrillo Reveles, Veremundo, "Las Américas, una historia de novelas. El Concurso Literario de la Unión Panamericana como instrumento diplomático", Revista Historia de América, № 156, enerojunio 2019, p. 279-319.

Cilento, Laura, "Hacia un cronotopo rioplatense en Borges: su lectura de La tierra purpúrea de Guillermo E. Hudson", Letras, №38-39, 1998-1999, 49-57.

Cohan, Oscar, Carta a Samuel Glusberg, Buenos Aires, 14/04/1941, CeDInCI, Fondo Glusberg.

---, Carta a Samuel Glusberg, Buenos Aires, 26/05/1941, CeDInCI, Fondo Glusberg.

Espinoza, Enrique, “Homenaje escolar a Hudson”, Trinchera, Buenos Aires, Babel, 1932, p. 78-85.

---, "La reconquista de Hudson", Repertorio Americano, 20/10/1934, p. 233-234.

---, "Intención de este homenaje", SECH, Año 1, N 6, octubre 1937, p. 27.

---, “Hudson descubre una librería de viejo en Buenos Aires”, Atenea, Tomo LVIII, No 172, octubre 1939, p. 56-61.

---, "El diario, la revista, el libro", Babel, Año XXI, N 17, mayo-junio 1941a, p. 37-43.

---, “La reconquista de Hudson”, Babel, Año XXI, N 18, julio-agosto 1941b, p. 67-88.

---, Tres clásicos ingleses de la pampa, Santiago, Babel, 1951.

Ferretti, Pierina y Lorena Fuentes, "Los proyectos culturales de Samuel Glusberg. Aportes a la historia de la edición independiente en la primera mitad del siglo XX latinoamericano", Andamios, vol. 12, N²9, 2015, p. 183-206.

Franco, Luis, Carta a Samuel Glusberg, 4/10/1940, CeDInCI, Fondo Glusberg.

Fuentes, Lorena, “Samuel Glusberg y José Carlos Mariátegui. Observaciones a propósito de las políticas editoriales de las revistas Babel y Amauta", Cuadernos del pensamiento latinoamericano, $\mathrm{N}^{\circ}$ 20, 2013, p. 1-24.

González Vera, José Santos, “Enrique Espinoza”, Algunos, 2ª ed., Santiago, Nascimento, 1967, p. 33-55.

Lencina, Eva, “"'Nada menos que todo un gaucho": la presencia de William Henry Hudson como emblema en la obra de Luis Franco", Argus- $a$, vol. VI, № 23, febrero 2017. 
---, “Canon y nacionalización: la edición y difusión de la obra de W. H. Hudson a través de la "época de oro" de la industria editorial", RELEED, N 1, 2019.

Montenegro, Ernesto, “Hudson, novelista de la naturaleza”, Babel, Año XXI, Nº 18, julio-agosto 1941, p. 109-111.

---, “A sane view of Latin America. Carl Crow's impressions of our southern neighbors are set down with sympathy and understanding”, New York Times Book Review, 21/09/1941, p. 60.

---, Memorias de un desmemoriado, Santiago, Universitaria, 1969.

---, "An economic partnership of the democracies", The Annals of the American Academy of Political and Social Science, Vol. 222, julio 1942, p. 80-83.

Oxford Latin Dictionary, Oxford, Oxford University Press, 1968.

Pita González, Alexandra, Redes intelectuales transnacionales en América Latina durante la entreguerra, México, Universidad de Colima/Porrúa, 2016.

Pozzo, Fernando, “Semblanza de Hudson", Antología de Guillermo Enrique Hudson, Buenos Aires, Losada, 9-31.

---, "Prólogo", Guillermo Enrique Hudson, Allá lejos y hace tiempo, trads. Fernando Pozzo y Celina Rodríguez, Buenos Aires, Peuser, 1941 [1938], p. 9-10.

Rojas, Manuel, "El animismo de Hudson", Babel, Año XXI, N 18, julio-agosto 1941, p. 102-108.

Sapiro, Gisèle, "How do literary works cross borders (or not)? A sociological approach to world literature", Journal of World Literature, $\mathrm{N}^{\circ}$ 1, 2016, p. 81-96.

Siskind, Mariano, Deseos cosmopolitas. Modernidad global y literatura mundial en América Latina, trad. Lilia Mosconi, Buenos Aires, Fondo de Cultura Económica, 2016 [2014].

Spivak, Gayatri Chakravorti, “Can the subaltern speak?", Cary Nelson y Lawrence Grossberg, eds., Marxism and the Interpretation of Culture, London, Macmillan, 1988, p. 271-313.

Tarcus, Horacio, Mariátegui en la Argentina o las políticas culturales de Samuel Glusberg, Buenos Aires, Ediciones El Cielo por Asalto, 2001.

--- (ed.), Cartas de una hermandad. Leopoldo Lugones, Horacio Quiroga, Ezequiel Martínez Estrada, Luis Franco, Samuel Glusberg, Buenos Aires, Emecé, 2009.

--- (ed.), "Las políticas culturales de Samuel Glusberg: Correspondencias mariateguianas entre Buenos Aires, Santiago, Lima y La Habana", Políticas de la memoria, № 16, 2015-2016, p. 124-166.

"To weigh defense plans. Dartmouth Conference will study problems of the Americas", The New York Times, sección B, 6/11/1940, p. 21.

Verdugo, Mario, “Geoerótica: corporizaciones del territorio en el criollismo chileno", Acta Literaria, $\mathrm{N}^{\circ} 48,2014$, p. 33-47.

Viu, Antonia, "Lloremos y traduzcamos. La Segunda Guerra Mundial y la Cooperación Intelectual desde Babel. Revista de revistas (1939-1940)", Rafael Gaune y Claudio Rolle (eds.), Homo dolens. Cartografías del dolor: sentidos, experiencias, registros, Santiago, Fondo de Cultura Económica, 2018, p. 418-434. 


\section{NOTAS}

1. Enrique Espinoza era el popular seudónimo del editor judío-argentino Samuel Glusberg. En adelante, escribo "Enrique Espinoza" por ser este el nombre con que el editor firmaba sus textos y por el cual era mayormente conocido en su época.

2. William Henry Hudson (Quilmes, 1841-Londres, 1924) ("Guillermo Enrique" para los latinoamericanos) es uno de los principales escritores y naturalistas ingleses del cambio de siglo. Sus primeros 33 años de vida transcurrieron en la pampa argentina, donde mantuvo una intensa y decisiva relación con la naturaleza circundante, de la que bebe en buena parte su filosofía. Se crio en su casa, según la preceptiva inglesa, y partió a Inglaterra en 1874. Comenzó a publicar su obra, en inglés y para ingleses, en 1885. Nunca volvió a Argentina, pero sus experiencias allí (y el imaginario latinoamericano) son la base de numerosos libros, entre los que suelen citarse The Purple Land (1885), Idle Days in Patagonia (1893), El ombú (1902), Green Mansions (1904) y Far Away and Long Ago (1918).

3. Babel tuvo una etapa argentina (1921-1929) y luego una chilena (1939-1951).

4. La mayoría de los estudios sobre Babel provienen de la historia intelectual y de la sociología de la cultura. Ellos han contribuido a delinear el derrotero político, ideológico y cultural de Espinoza, así como algunas de las redes transnacionales que tejió o bien sus posiciones en los campos culturales argentino y chileno (Tarcus, 2001, 2009, 2015-2016; Fuentes 2013; Ferretti y Fuentes 2015; Hernández 2012, 2019-2020). Viu ha propuesto una entrada a la revista desde la materialidad. Creo que esa mirada y una perspectiva de redes que repare en las múltiples interpretaciones del conjunto puede ayudar a contrapesar la magnitud que las posiciones y la actuación de Espinoza ha tenido para pensar la significación de la revista y, por extensión, el lugar que le cabe a Hudson en ese proyecto.

5. El mismo Glusberg describió esto en su artículo "El diario, la revista, el libro": "A veces una misma idea puede hallar su primera forma incipiente en el diario, ser desarrollada luego, con más detención, en la revista, y alcanzar, por último, la plenitud del libro" (1941a: 37).

6. En 1938, Pozzo había publicado la traducción de Far Away and Long Ago [Allá lejos y hace tiempo] en conjunto con Celina Rodríguez, por editorial Peuser; Montenegro, la de Green Mansions [Mansiones verdes], por editorial Zig-Zag.

7. Se observa en los comentarios sobre La tierra purpúrea, "El ombú" y la traducción de Mansiones verdes a cargo de Montenegro.

8. Mario Verdugo (2014) ha estudiado la metáfora sexual que marca con gran regularidad la representación del territorio en el corpus del criollismo chileno.

9. Espinoza lo considera como un maestro en la captación de una esencia histórico-política argentina a través de episodios costumbristas, como el juego del pato, ya folclórico. En concordancia con ello, incluye el apéndice a su cuento "El ombú", sobre el que comenta: "a fin de que el lector aprecie el método seguro con que el sabio naturalista trabajaba sus obras de arte. Las consideraciones sociales y políticas que Hudson anota de paso en este Apéndice acerca de Rosas y su pueblo parecen de ahora. Y ninguna gloria mayor para un novelista que ésta de parecer [...] de siempre por aquello que es invariable en el hombre y la naturaleza" (1937: 27). En cuanto a la crítica tácita, está dada por la inclusión del fragmento "Un viejo recuerdo", que es explicado y dirigido contra la estética criollista en "La reconquista de Hudson" (1941).

10. Cunninghame Graham, escritor inglés y confidente de Hudson, es otro de los nombres que Glusberg canoniza, pero con una intensidad bastante menor que la de Hudson. Ambos, sumados a Francis Bond Head, son sus "clásicos ingleses de la pampa" (Glusberg 1951).

11. Es claro que esta operación de mundialización del editor-banca implica la importación de una mercancía con valor agregado que se ha producido en el centro. La literatura de Hudson se ha acuñado en lengua extranjera, por un medio-extranjero y para extranjeros. Es eso lo que Espinoza importa, aun cuando la mirada de Hudson se rebele contra los intereses predatorios de 
las potencias coloniales. El criollismo trabajaría con la misma materia prima que Hudson, pero no poseería la técnica para producir un bien de valor universal. La pregunta es entonces cómo crear un universalismo otro, lo que implica interrogar la técnica legada por el inglés.

12. Con este símil, Espinoza reconducía y afinaba una relación que había presentado ya en "Homenaje escolar a Hudson", su primer texto sobre el autor: "Niños: / Mañana, cuando ustedes egresen de la escuela Guillermo Enrique Hudson y oigan de los hombres que no se ocupan de pájaros que es necesario estudiar el inglés para hacerse ricos, pueden decirles: Sí, estudiaremos el inglés, pero solo para leer y traducir a nuestro grande y querido Guillermo Enrique Hudson" (1932: 85).

13. El doctor Fernando Pozzo se había acercado en 1935 a la Municipalidad de Quilmes para lograr la compra de los derechos de traducción de Far Away and Long Ago. Esta aparecería en 1938 por editorial Peuser (y fue hecha en conjunto con Celina Rodríguez). En el prólogo de esa edición se lee: "He creído que esa obra, aparte de su belleza, que lo ha hecho un clásico de la literatura inglesa, tiene un valor documental folklórico para la historia de nuestra campaña" (Pozzo 1942: 9). En un texto posterior, "Semblanza de Hudson" -incluido en su Antología de Guillermo Enrique Hudson (1941), libro que consagra el esfuerzo canonizador ligado a Sur- continúa esta veta, desconsiderando la clave social que guiaba a Glusberg: Hudson sería "también un folklorista eximio", con un "conocimiento más profundo de la vida de los gauchos y de su manera de hablar. Es realmente admirable cómo en inglés ha dado una interpretación tan justa del lenguaje usado en las pampas" (Pozzo 1941: 24). Es decir, celebra justamente el aspecto que Glusberg critica: cierta fidelidad lingüística vernácula.

14. En esta línea, Borges había propuesto hablar del Río de La Plata más que de Argentina, en una de sus principales contribuciones para superar la horma nacional en la interpretación de Hudson (Cilento 1998-1999: 55).

15. Mi comentario sobre este texto no pretende ser exhaustivo, sino que solo atiende a los puntos generales de interés para el argumento. Para un análisis con mayor detalle, ver Lencina 2017.

16. Por ejemplo, en noviembre de 1940 dio uno de los cinco discursos de la conferencia "Defense of the Americas", auspiciada por el Dartmouth College. Allí compartió podio con el asistente ejecutivo de Nelson Rockefeller, con un representante de la Academia Militar de Estados Unidos y con otro de la división económica del estado. Montenegro es simplemente presentado como "Chilean journalist and author" (1940: 21).

17. Como botón de muestra, léase el comentario sobre un libro que aprueba: "Before closing I wish more of the writing about Latin America (and all foreign impressions, for that matter) could come from tempered minds and sympathetic natures of the kind the present author is endowed with, for then we should save ourselves a tremendous deal of hasty judgment, patronizing attitudes and downright silly conclusions" (Montenegro 1941b: 60).

18. "Que los padres de Hudson fueran norteamericanos y de raza distinta, nada les significa. Eran ingleses, a pesar del jus soli y del home rule" (Espinoza 1939: 58).

19. En su faceta de naturalista, el mismo Hudson se identificó con este tipo de pensamiento; de ahí su An Introduction to the Philosophy of Herbert Spencer (1894).

20. Este texto forma parte de una investigación doctoral en curso acerca del proyecto de Babel en Chile, financiada por la beca CONICYT-PFCHA/Doctorado Nacional/2019-21192077. Agradezco a Carlos Walker y a Andrea Kottow por sus generosos comentarios a una versión previa del artículo. Los errores son de quien escribe. 


\section{RESÚMENES}

En este artículo analizo algunas de las interpretaciones que obtuvo la obra de Guillermo Enrique Hudson en la etapa chilena de la revista Babel. Propongo que la canonización de Hudson impulsada por Enrique Espinoza fue una estrategia para repensar la identidad cultural latinoamericana en el contexto global de la Segunda Guerra Mundial, que sin embargo tuvo un énfasis nacional-popular. Una canonización americanista y universalista de Hudson se hizo efectiva solo con las interpretaciones que aportaron colaboradores no argentinos de Babel. Para comprender la significación de este nombre y de esta obra en el proyecto de Babel atiendo a los discursos y a las redes que proyectó el número de homenaje a Hudson.

Dans cet article, nous analysons certains interprétations suscitées par les travaux de Guillermo Enrique Hudson dans les projets éditoriaux de Enrique Espinoza, notamment au Chili. Nous proposons que la canonisation argentine d'Hudson faisait partie des pratiques d'édition avec lesquelles Espinoza cherchait à repenser l'identité culturelle de l'Amérique Latine dans le contexte global de la Deuxième Guerre mondiale. Pourtant, l'universalisation de son nom s'est produit, en fait, à travers les interprétations apportées par les collaborateurs non argentins de la revue Babel. Pour le démontrer, nous nous concentrons aussi bien sur le rôle des discours, que sur celui des réseaux auxquels a participé Espinoza.

In this article I analyze some interpretations of the work of Guillermo Enrique Hudson in the Chilean phase of Babel magazine. I propose that the canonization of Hudson undertaken by Enrique Espinoza was a strategy to rethink Latin American cultural identity in the global context of World War II, which had, nonetheless, a national-popular accent. Hudson's decisive Americanization and universalization came with the interpretations contributed by nonArgentine collaborators of Babel. To comprehend the signification of Hudson's name and work, I analyze the discourses and the networks that the homage issue projected.

\section{ÍNDICE}

Mots-clés: Enrique Espinoza, Guillermo Enrique Hudson, réseaux éditoriaux, Latinoaméricanisme, littérature mondiale

Palabras claves: Enrique Espinoza, Guillermo Enrique Hudson, redes editoriales, latinoamericanismo, literatura mundial

Keywords: Enrique Espinoza, Guillermo Enrique Hudson, editorial networks, latinamericanism, world literature

\section{AUTOR}

\section{PABLO CONCHA FERRECCIO}

Universidad de Chile

pabloconchas@gmail.com 